\title{
Contextual and Environmental Health Protection and Risk Factors that are not taken into Consideration in the Routine Medical Consultation
}

\section{Turabian JL*}

Specialist in Family and Community Medicine, Health Center Santa Maria de Benquerencia, Spain

*Corresponding author: Jose Luis Turabian, Health Center Santa Maria de Benquerencia Toledo, Spain, Email: jturabianf@hotmail.com

\section{Review Article \\ Volume 3 Issue 3}

Received Date: November 16, 2019

Published Date: December 20, 2019

DOI: $10.23880 /$ eij-16000133

\section{Abstract}

Medicine tends to be a holistic discipline, according to which the individual should be treated as a whole and provide comprehensive biopsychosocial health care and also in relation to the environment. The effects of climate change on the disease burden require the doctor to make a "situation diagnosis": that is, to get an idea of the interaction of man with his context. From the general medical care level there are a number of possibilities of including the environmental nuance in clinical tasks with patients, which have protective and health promoting effects, individually and with global ecological repercussions: 1) The therapeutic contexts (those places, situations or contexts that achieve both physical and psychic environments associated with an improvement of health or well-being): the healing power of the environment and nature (green spaces, forests, parks, open spaces, and gardens personal, walking-for-thinking, living with a companion animal); 2) To be aware of the ecological repercussions of the "micro" decisions: Ecological and environmental effects of the prescription of certain drugs, of the dietary advice, preventive approaches for patients in the consultation that are based on environmental measures (as in osteoporosis, prevention of skin cancer, etc. 3) Promote the human factor: contextual circumstances in the relationship which can condition listening, and therefore, diagnosis and intervention; 4) Change the perception of the environment: mental landscapes, through artistic creation, etc and 5) Pharmaceutical contamination of nature, secondary to polypharmacy and therapeutic non-compliance: generalized contamination of river systems worldwide with antibiotic compounds, pharmaceutical contamination at sea, drug contamination is concentrated in insects and passes to the Predators. In short, in general medicine, tasks carried out at a small caliber level can subtly tilt the world towards ecology, dignity, compassion, and health.

Keywords: Family Medicine; System Medicine; Ecology; Ecosystem; Environment and Health; Nature and Health Benefits; Essential Social Connections; Ecological Therapy; Epidemiology 


\section{Epidemiology International Journal}

\section{Introduction}

Health is the perfect correspondence between an individual and his environment-context. Thus, human contexts and the meaning of human environments for people who live and work in them, are important determinants of the effectiveness and generalization of interventions to improve the quality and safety of medical care. But, despite the importance of the context, in health care is generally not taken into account, nor is the specific mechanism by which local contexts affect the implementation of improvement interventions studied and assessed [1].

There is a recognition that organic, psychological, and social health constitute a common field of study, so that in some diseases physical factors predominate, in others psychic ones, and in others social ones, but for all health problems co-exist bipsicosocial elements in their etiology, symptomatology and treatment [2].

Therefore, cases of illness presented by people cannot be treated by considering them in isolation from each other and from the context to which they belong. It has been established for a long time that this forces the health professional to turn their attention to the circumstances of the home and to the consideration of the man in his family, work and community context [3].

Climate change is already threatening many health achievements of the past 50 years and will continue to do so at an accelerated pace unless action is taken. WHO estimates that climate change will cause an additional 250,000 deaths per year by 2030, if only five exposure routes were taken into account: malnutrition, malaria, diarrheal disease, dengue and heat.

Our understanding of how climate change affects health continues to grow, but we know that it will have multiple direct and indirect negative effects, including increased morbidity related to heat, malnutrition, increased waterborne and food borne diseases and mental health problems Although the effects of climate change on health are far-reaching, they can still be mitigated if action is taken now.

Climate change threatens to undermine the achievement of universal medical care through negative health outcomes and alterations in the health system. Many regions of the world with the greatest vulnerability to climate change are also those with the lowest health care coverage. They must fight for evidence-based climate adaptation that protects health and prioritizes the climate resilience of the health system [4].
The effects of climate change on the disease burden are reflected in:

Non-communicable Diseases: A temperature increase of $1{ }^{\circ} \mathrm{C}$ is related to a $3 \%$ increase in cardiovascular mortality, a $4 \%$ increase in respiratory mortality and a $1 \%$ increase in cerebrovascular mortality. High temperatures are related to a $6 \%$ increase in hospital admissions for coronary heart disease; cardiovascular events are also associated with exposure to air pollution, such as the by-products of burning fossil fuels and ozone, which is amplified by temperature changes. Higher temperatures, forest fires, more severe and prolonged pollen seasons, and ground-level air pollution such as ozone and fossil fuel burning, increase the burden of respiratory diseases. It has been reported that the incidence of diabetes increases by 0.314 per 1000 people for every $1^{\circ} \mathrm{C}$ temperature increase. Extreme weather, forced displacement and violence can precipitate mental health problems; Extreme heat can exacerbate existing conditions. Chronic kidney disease of unknown origin has been linked to increased heat stress in many regions, especially in farming communities.

Infectious Diseases: Vector capacity for malaria transmission has increased by more than $20 \%$ at the highest elevations in Africa since 1950. WHO predicts significant future increases in mortality due to increases related to climate change in malaria in the regions Central and eastern sub-Saharan Africa. Since the 1950s, vector capacity for dengue transmission has increased by $10 \%$. Warmer ambient temperatures have been associated with food borne illness, such as salmonella. A $1^{\circ} \mathrm{C}$ increase in temperature can lead to a $0.8-2.1 \%$ increase in hand, foot and mouth disease.

Occupational Injuries: At higher temperatures, the risk of work-related injuries and illnesses increases among indoor and outdoor workers. Outdoor workers, in particular, face an increased risk of heat-related illnesses as heat waves become more frequent and last longer.

Other Effects of Climate Change: These are, population displacement and migration, rising poverty, disruption of healthcare infrastructure and care delivery health workforce, with disruptions and impairments. Extreme weather events related to climate change, like more intense hurricanes and floods, can cause structural damage or power outages at healthcare facilities; Even undamaged facilities can be affected by supply chain disruptions - due to factory disruption, increased demand, or transportation disruptions - and subsequent resource shortages [4]. 


\section{Epidemiology International Journal}

In this scenario, in addition to a level of global actions and decisions, whose goal to improve the health and quality of life of all people, general practitioners (GPs) at the most basic level of general medicine should not go through High the effects that climate change will have on disease burden and health infrastructure. Only through bold, innovative and interdisciplinary action can these unprecedented complex challenges be addressed and ensure a healthier world for future generations.

This article, based on a selected review and the author's experience, aims to reflect, conceptualize and synthesize the interactions that exist between environment, health and medical care, including contextual and environmental risks created during medical work and their practical repercussions from the point of view of general medicine.

\section{Discussion}

The effects of climate change on the burden of disease require the doctor to make a "situation diagnosis": that is, to have an idea of globality, context, and the interaction of man with his context. The idea of an isolated man which can be studied or understood in the abstract, outside of any social or cultural context, must be left behind [5].

In the discussion around these concepts of climate change, ecology and health, the old individual - society dichotomy beats in the background. Who does who? Does man to society, or society to man? The concept of "man in situation" or "in context" supposes an overcoming of that dichotomy [5].

From the general medical care level there are a number of possibilities of including the environmental nuance in clinical tasks with patients, which have protective and health promoting effects, at the individual level and with global ecological repercussions on the effects climate change, disease burden, and health infrastructure (Table 1).

\begin{tabular}{|c|c|}
\hline Clinical Factors & Examples of Environmental Health Protection and Risk Factors \\
\hline 1. Therapeutic contexts & $\begin{array}{l}\text {-Benefits for the health of being near green spaces } \\
\text {-Walking-for-thinking } \\
\text {-Benefits for the health that brings to live with a companion animal }\end{array}$ \\
\hline $\begin{array}{l}\text { 2. Ecological repercussions of "micro" } \\
\text { decisions (in the individual patient) }\end{array}$ & $\begin{array}{l}\text {-Ecological and environmental effects of the prescription of certain drugs } \\
\text {-Ecological and environmental effects of the dietary council } \\
\text {-Preventive approaches for patients in the consultation that are based on } \\
\text { environmental measures }\end{array}$ \\
\hline 3. Human factor & $\begin{array}{l}\text {-Contextual circumstances of the relationship } \\
\text {-Sometimes, do nothing: just be there }\end{array}$ \\
\hline $\begin{array}{l}\text { 4. Change the perception of the } \\
\text { environment }\end{array}$ & $\begin{array}{l}\text {-Mental landscapes } \\
\text {-Artistic creation }\end{array}$ \\
\hline $\begin{array}{l}\text { 5.-Pharmaceutical contamination of } \\
\text { nature (emerging pollutants) }\end{array}$ & $\begin{array}{l}\text {-General contamination of river systems worldwide with antibiotic } \\
\text { compounds } \\
\text {-Pharmaceutical contamination at sea } \\
\text {-Contamination by drugs is concentrated in insects and passes to predators }\end{array}$ \\
\hline
\end{tabular}

Table 1: Some Clinical Factors with Health Protective and Promoting Effects at the Individual Level and with Global Ecological Implications.

\section{The Therapeutic Contexts}

Special attention is being given to the growing shift in the biomedical attitude which goes from a pathogenic concept of the disease to a more salogenic perspective. This turn should lead to a better quality of medical care and strengthen health processes. Traditionally, the pathogenic view has tended to consider patients as objects and focused on the "diseased" parts of the human body, which was increasingly divided into smaller parts and treated separately. Other consequences of pathogen perspective have been that the psychological, social and spiritual needs of patients have been largely ignored in the design of health service facilities, and often marginalized in the philosophy of providing care. The emphasis on functional efficiency, along with the pathogenic conception of disease and 
health, has often produced health centers that are not psychosocial support.

In recent years, however, a different perspective has emerged that leads to a new paradigm. In this new paradigm, the focus is on patients: with their physical, psychological and social health, and greater emphasis is placed on the performance of care activities and on the design of health care settings. Future research has to develop the philosophy of care that focuses on a broader concept of health, thus creating an awareness of the importance of psychosocial support design, context and the environment [6].

The therapeutic contexts are those places, situations, contexts, etc., that achieve both physical and psychic environments associated with a therapeutic strategy or improvement of health or well-being. The "therapeutic contexts" favour the healing process by constituting physical or psychic environments that create "safe" places, literally an energy capsule of support and care.

The "landscape" or context can not only be considered as a physical environment, built or modified by human action, but also as a product of the human mind and material circumstances, which reflects intentions and actions as well as barriers and structures that society imposes. Contexts can provide a meaning of identity and feelings of security, such as places where family life is done (home), work, or usual meeting places (such as doctors' consultations). These places where people have had Interpersonal support networks which been produced for a long time, can promote healing. These places provide a "psychological root" that has been achieved through a long permanence and the establishment of certain relationships with the context, which produces feelings of self-identity and security. This environment can be understood as a "personal home" that provides a comprehensive social network of physical, spiritual and psychological factors that emerge together to promote the creation of a healthy or healing place.

\section{Poverty or Violence Environments are Associated} with Worse Health Outcomes: It has been reported that children living in areas with elevated rates of violent crime and higher density of liquor stores had shorter telomeres and aberrant cortisol functioning. Living in indigent neighbourhoods has been associated with poor academic and behavioural outcomes in children. The findings are consistent with studies showing impaired cortisol levels, shortened telomeres, or both, in children raised in stressful situations, such as being reared by depressed mothers. It is unknown whether aberrant telomere length and impaired cortisol functioning have long-term consequences. Clinicians treating patients from high-risk areas can assume the existence of biological impediments to healthy psychiatric functioning [7].

The Emergence of New Understandings of the Environment: It is well established that natural environments affect human health and wellbeing. Discussions of this relationship have often, however, been overly deterministic, focusing upon environmentrelated social determinants of health such as the neighbourhood, transport and so forth. This determinism is at odds with developments that have led to the emergence of new understandings of the environment, informed by disciplines including anthropology, geography, Science and Technology Studies and environmental sciences. In these perspectives, the environment is more than a resource; it is a dynamic geographic space, invested with cultural and social meaning, and a sense of identity [8].

Natural Environments affect Human Health and Wellbeing: The healing power of nature, "vis medicatrix naturae", has traditionally been defined as an internal healing response designed to restore health. Almost a century ago, the famous biologist Sir John Arthur Thomson provided an additional interpretation of the word nature within the context of vis medicatrix, defining it as the natural, unbuilt external environment. He argued that the healing power of nature is also associated with conscious contact with the lively and inanimate natural portions of the outdoor environment. A century later, global environmental concerns, rapid urban expansion and mental health disorders at crisis levels may be related to the decrease in contact with nature. It is probably necessary to revisit Sir J. Arthur Thomson's claim that the healing power of the naturebased environment (green spaces, forests and parks in particular) extends to the field of mental health and vitality [9].

Interactions between Landscape, Natural Environment and Health: Landscape and Health: Landscape is a crucial element in researching the relationship between environment and well-being. Human social agents are embedded in particular landscapes, and it is in landscapes that environmental changes are experienced, which can have implications for well-being. Landscape is understood here as an assemblage of different forms of matter, animate and inanimate objects, as well as symbolic and cultural processes [10].

Landscape context - its textual and sensory aesthetics positively shapes experiences and perceptions of the landscape, for those people who seek out natural environments for health. While health promotion is 
designated along the lines of encouraging choice or improving access to natural environments, physical activities are intertwined with atmospheres and affects emanating from the natural and human world [11].

Health Benefits of being near Green spaces: For people, the health benefits of being near urban green spaces can play a significant role in well-being and quality of life. It is often believed that health is the result of personal choices, such as diet or how often to exercise. However, it is now recognized that the surroundings, from home to the neighbourhood, are equally important for promoting health. Exposure to green spaces, such as public parks or forests, is linked with lower risks of all sorts of ailments common in the developed world -including cardiovascular disease, obesity, diabetes, and mental distress - and even of mortality. Experimental work has demonstrated myriad physiological responses that occur when people spend time in natural environments: blood pressure drops, heart rate decreases, immune function improves, and the parasympathetic nervous system directs the body to rest and digest [12].

The aesthetic value of parks, trees and open spaces has been widely praised for centuries. In recent decades, scientists have discovered a deeper level of impact. Studies have documented the connections between nature's experiences and human health, wellbeing, and treatment. The evidence confirms that the experiences of the trees, parks and gardens of the city can help with the restoration of attention and stress reduction, contribute to positive emotions and can promote social commitment and social support (among neighbours, friends, family and local organizations). There are also specific health benefits, such as those for mobility, isolation, depression and Alzheimer's. Living in a community with roads accessible to parks and gardens are essential for maintaining good health and a positive mindset. Maintaining these opportunities is particularly important for older adults.

The designs of the neighbourhood environments that facilitate people's outdoor activities have health repercussions. The quality and character of a neighbourhood's environment (for example, places to sit outdoors) influences the residents' real outdoor activities and the perceived quality of life (satisfaction and physical health). The amount of green spaces in a neighbourhood is positively associated with health. The aesthetic quality of the nearby open spaces is related to the satisfaction of people's lives. To having safe routes and paths to open spaces correlates with greater walking behaviour, regardless of age, physical ability and education of a person [13].
Brief Experiences with Nature in Public Spaces within the City and in Personal Gardens: People have sensed for decades that access to green space benefits all people. Many people cherish nature experiences in their lives, and enjoy getting away from it all in the great outdoors, often beyond the city. But we now know that brief encounters within the city, within public spaces and in our personal gardens, provide many benefits. Those individuals who are more vulnerable benefit the most, including some older adults. Evidence of green space health benefits for elders extends across the social, mental, and physical domains. Walkability and community amenities that strengthen people's minds, bodies and spirits are essential in the design of future urban places. As we age we may become less mobile, and we must rely on the nature experiences that are closest to home. As communities plan and design for nature access for residents, age-based considerations should be on the checklist [13].

Walking-For-Thinking: Walking has long been associated with thinking. Anecdotal evidence from philosophers, writers, researchers, artists, business leaders and so forth testify to the powers of walkingfor-thinking. Has been communicated that walking-forthinking as a specific form of walking that has a steady rhythm and a specific individual speed that is experienced as most conducive to thinking. Further, the subjects experience walking-for-thinking as moving gestalt, interplay between the person, environment and thinking where the rhythms of the body correlate with the rhythm of walking, affording feeling of enhanced memory and creativity [14].

Health Benefits of Living with a Pet: A companion animal can make the person more responsible, it is a source of motivation, of a better organization, of having a daily routine, especially to maintain a schedule of food or walks. This is especially important in the case of those who are depressed or who lead a life that is too sedentary. It makes people feel less alone. This is especially important in the case of people who live alone or have recently suffered a significant loss, regardless of their age. It helps people feel less stressed. It allows socializing with more people. It makes people more empathetic. This is especially important in the case of children: living with a pet from a young age helps them to be more respectful, empathic and sensitive to other animals and people. They help express emotions. Biological benefits have also been described. For example, dog ownership tied to better survival after cardiovascular events. Dog ownership is associated with lower mortality risk in adults, especially those with cardiovascular disease. The collective evidence to date is that the association between dog ownership and improved survival is real, and is likely at 
least partially causal. Dog ownership can lead to greater physical activity and decreased loneliness, among other benefits [15-17].

Similarly, for example, Swedish infants living with dogs or farm animals had decreased risk for asthma at ages 3 to 6 years. The hygiene hypothesis posits that exposure to a greater variety of microorganisms during childhood may decrease the risk for chronic inflammatory diseases. Dogs also appear to be somewhat protective, whether or not there is a family history of asthma. These results are likely generalizable to other European and North American societies [18].

Contexts in Health Centers: Architecture has the power to modify those who live there, both physically and mentally. Each building presents opportunities to promote or prevent healthy, positive relationships, and connections with the environment. It is the job of the architect to identify these opportunities and, as far as possible, to aim their work in the right direction. The difference between alienation and connection depends not only on social and economic forces, but also on countless "micro" incidents such as those that occur when two neighbours are chatting on the sidewalk, when a family talks at the table after dinner, when a child who falls asleep to the sound of its parents' voices outside porch.

Healing is possible, in part, through space. To achieve adequate space, the integration of natural light, colour and natural and green spaces must be achieved, both inside and around the building. Scale, light and ventilation are basic elements, but comfort and beauty are also essential in a patient's well-being. In order for a hospital or a health center to have the capacity to heal, it must be properly organized in architectural terms, but also, to being comfortable and manage to overcome that sense of confinement that these buildings often cause.

The GP cannot change or build buildings, but it is important that he understand how they influence health, and as much as possible adapt the buildings that patients use, so that they promote health [19-21].

For example, there is a therapeutic approach based on the location, layout and interior design of psychiatric institutions, which linking between meteorological parameters, specifically air and sun, and mental illness treatment [22]. Also, hospitals and other health centres should not look like disease centres. There are other architectural forms that bring us closer to health and healing: for example, in them, the courtyards are projected inwards, reversing the traditional concept of facade, as responsible for allowing the entry of light and protect from unwanted views.

And also, there are other places or contexts that bring us closer to health and healing: any type of assistance at home, such as long-term care for an invalid patient, or planned birth at home, allows to GP to use the qualities of that environment to obtain therapeutic effects.

\section{To Being Aware of the Ecological Repercussions of "micro" decisions (in the individual patient)}

A series of relationships can be established between people and ecosystems (agricultural, urban, biophysical, and socioeconomic), and associated interventions that have implications for the role of the GP who attends patients every day:

A. The ecosystem as a source of exposure to diseases (toxic pollutants from air, land and water, disease vectors, climatic changes, etc.) and interventions in relation to risk management, legislation, and health protection

B. The ecosystem as a condition for human well-being (social and economic environment, peace, security, education, food, sustainable resources, justice and social equity, lifestyles, places of residence and work, healthy cities), and interventions in relation to healthy and sustainable environments

C. The ecosystem as a core of human values (includes the welfare of species other than man, environmental justice: an "ethical land"

Thus, the following examples of application in the daily work of the GP can be cited:

Ecological and Environmental Effects of the Prescription of Certain Drugs: Massive logging in Africa of a species native to the plum family, the Prunus Africanus tree (from whose bark a substance used, without a clear scientific basis, to treat prostate diseases in the West) is extracted, by companies European pharmaceutical companies, although it is an internationally protected species, makes this tree now in danger of extinction in certain African regions, favouring the loss of soil fertility and the consequent food insecurity of its population) [23]. Thus, Mount Kenya, the highest mountain in Kenya, and the second highest in Africa (after Kilimanjaro), which is the sacred mountain of the Kikuyu (the largest ethnic group in Kenya, comprising a population of more than 5 million people, $20 \%$ of the total population of Kenya) and 
declared a World Heritage Site by UNESCO in 1997, is being destroyed by the illegal exploitation of its forests, the cultivation of marijuana and abrasive agricultural practices.

More than 15,000 native trees have been felled. Among the set of felled trees, it should be noted the massive felling of Prunus africana, but also camphor, cedar and tropical olive trees, and $90 \%$ of the forest mass has been destroyed in an area of 13,000 hectares. In this area without trees, more than 3,000 hectares have been used for cultivating miraá (marijuana).

Likewise, the example of prescription of drugs composed of Saw palmetto as treatment of the symptoms of prostatism can be cited. Although it has been claimed that the extract of saw palmetto is an herbal remedy for benign prostatic hyperplasia, in fact, it is an ineffective treatment. Serenoa repens or Sabal serrulata, commonly known as saw palmetto or dwarf palm heart, is the only species currently classified in the genus Serenoa; the dwarf palm heart is a perennial plant that belongs to the Arecaceae palm family. It is a small palm that grows to a maximum height of about 2$3 \mathrm{~m}$. The wild palmetto is native to the southeastern Europe and northern Africa, and is endemic to the subtropical south-eastern United States, most commonly along sand plains and hills of the South Atlantic and the Gulf. It grows in bushes or dense thickets in sandy coastal areas, and as understory in pine forests or hardwood shrubs. It is a resistant plant; of extremely slow growth and long life, with some plants, especially in Florida, which may be $500-700$ years old.

Palm trees are the most important group of plants in the Amazonian forests, where they have a great importance in their composition, dynamics and structure, and therefore in maintaining their ecological balance, with a very important role for the local communities that live in these forests.

These environments are the source of the resources used in the construction of their homes, in the manufacture of utensils, and even in many cases are used for medicinal purposes. But, the populations of palms have diminished in a remarkable way, due to its overexploitation and to the deforestation of the forests where they grow [24].

Ecological and Environmental Effects of Dietary advice: Ecological diet and Dietary advice about Chocolate, Palm Oil, Soybeans and Beef: Following an environmentally friendly and natural diet means reducing the possibility of pesticides and other chemicals that damage land, flora, fauna and human health [25]. If you are looking for a healthier and more environmentally friendly diet, it is possible to go to locally produced foods that are less processed and, above all, unpackaged foods or those do not require a large transfer beyond being organic, as food transportation and packaging. They are large environmental pollutants that in one way or another also harm health. That is, it can be tried on respect the cycles of nature in food production and that undoubtedly favours the care of the environment [26].

Another example in the GP's dietary advice is chocolate. It can be said that "Every time someone bites a chocolate bar, a tree is cut." During the last decade, deforestation has accelerated in West Africa, the source of two-thirds of the world's cocoa. According to one estimate, the loss of tropical forests last year increased more in Ghana and Ivory Coast than anywhere else in the world. It is largely the work of hundreds of thousands of poor cocoa farmers who seek to expand their plots by cutting down mature trees, often in national parks and protected forests. Tropical deforestation is currently responsible for approximately 10 percent of global greenhouse gas emissions. Around the world, the pace of deforestation is alarming. In 2017, 40 football fields of tropical forests were lost every minute, stimulated by the growing demand not only for cocoa, but also for palm oil, soybeans, and beef (and also wood and rubber) [27].

In short, $60 \%$ of the risk factors responsible for all diseases are the result of a poor quality diet. This fact is associated with the health of the planet: the most harmful foods for humans are also for their Earth. Fruit, vegetables, potatoes, olive oil, legumes, nuts and cereals are the healthiest foods that also have minimal impact on the planet [28].

\section{Preventive Approaches for Patients in the Consultation that are based on Environmental Measures: The prevention of osteoporosis complications (falls and fractures) based on improvements in the patient's environment vs. drugs: more lighting, removal of physical barriers -stairs, adequate bathroom, etc.-, correction of visual and hearing defects, use of a cane).}

The prevention of skin cancer favoring more trees vs. protective creams, the advice about powdered detergent for a family when a child comes with eczema, the inappropriate use of antibiotics that alters the entire ecosystem, etc.

\section{Promote the Human Factor}

This vision must include the problems of the context in which the professional task is carried out (and that 
allow to begin to visualize these contextual circumstances in the relationship, that is, that can condition the listening, and, therefore, the diagnosis and the intervention) [5].

There can be no objective treatments without emotions. The interactions cause changes - either between the scientist and the object of scrutiny, or between the doctor and the patient. The interaction between two people generates real disturbances in the psychophysical state of both. There can be no completely neutral treatments. To think that there can be "objective" "non-emotional" treatments is only possible due to our blindness about the connectivity of human beings with the entire universe. The approach, rather than trying to minimize the subjective component in the healing process, is about maximizing it as it is a powerful force for change. Each patient has the potential to be their own healer. The concept of "patient-centered care" is a boomerang concept, since it affects the therapist at the same time: the treatment for the patient is self-treatment, and to cure another is to cure myself. For example, when the patient is a terminal, there are times when it is better for GP to do nothing: just be there

\section{Change the Environment or Change the Perception of the Environment}

Therapeutic landscapes can also be achieved mentally through imagination and visualization. Human ideas modulate the landscape; Human intentions create and maintain places. And our experience of a place and physical space modulates human ideas. They are examples of mental landscapes, a beach where the individual is relaxed listening to the sound of the waves, and feels with peace and total calm; the old home or the neighbourhood where he used to live, where one was accepted and was comfortable. These "landscapes" can be used in stress-related diseases.

Another way of accessing these images is through artistic creation, such as that performed in artistic therapy through various forms of visual arts, literature or poetry. That is, if a patient is stressed and is supposed to be stressed, due to their environment (work, family circumstances ...), they can improve with relaxation, exercise and reflection, even if it is not modified (because it is not always possible) the stressful environment. The world that surrounds each one, the environment of each one, is largely created by oneself because we are interpreting what surrounds us. Therefore, if the person varies the interpretation of their surroundings, in a way, it is as if their environment varies [29].

\section{Pharmaceutical Contamination of Nature (emerging pollutants), Secondary to Polypharmacy and Lack of Therapeutic Compliance}

The increasingly intense medical prescription of drugs (polypharmacy) and the increasing use of overthe-counter drugs, in most western countries, cause a recent contamination of surface waters due to these substances. The organisms of the people metabolize only a part of the majority of drugs that are prescribed and consumed, while the rest are expelled and, therefore, go to the drains and surface waters. The current treatment plants were designed to eliminate organic matter and pathogens, but they are not prepared to eliminate substances of as low concentration as the presence of many drugs, a situation that did not happen a few years ago.

Drugs can be introduced into water sources through wastewater that carries excreta from people and patients who have used them, and by inappropriate disposal of medications, for example, by throwing them down the toilet (in addition to agricultural liquid waste) [30].

In addition to the intake and elimination of nonmetabolized drugs, there is an inadequate disposal of pills, which are thrown down the toilets, instead of collection points for drug residues, which also contributes to this pharmaceutical contamination. In this regard, not only expired tablets end up in surface waters, but many prescriptions not consumed due to lack of adhesion [31].

About 20\% of European citizens still throw drugs (anti-inflammatory drugs, beta blockers, antibiotics, anxiolytics, among others) into the toilet, instead of taking them to pharmacies [32].

Thus it has been reported that the concentrations of antibiotics found in some of the world's rivers exceed "safe" levels up to 300 times. In a study of 14 antibiotics commonly used in rivers in 72 countries on all continents, traces of these medications (metronidazole, trimethoprim, ciproflaxacin) were found in $65 \%$ of the monitored sites. The "safe" limits were exceeded more frequently in Asia and Africa, but in Europe, North America and South America, there were also worrying levels that showed that antibiotic contamination is a global problem. The sites where antibiotics exceeded the "safe" levels were to a greater extent in Bangladesh, Kenya, Ghana, Pakistan and Nigeria, while one site in Austria was ranked as the highest of the European sites monitored. However, the greatest risk of pharmaceutical contaminants is found in densely populated and dry areas such as the Middle East [33]. 
Therefore, there is widespread contamination of river systems worldwide with antibiotic compounds, which could play an important role in the problem of antimicrobial resistance, and endanger the supply of drinking water. The culprits of the contamination of fresh water in Europe are now the drug residues (drugs for humans and animals) that waste cities, not industries.

Although the problem does not seem to affect humans directly yet, due to the low concentration of these drugs in fresh water, there are knowledge gaps; These include the lack of evaluation of the risks to human health associated with prolonged exposure to low concentrations of pharmaceutical products, and the possible combined effects derived from mixtures of pharmaceutical products. It would be convenient to confirm that the margins of exposure are suitable for potential sensitive subpopulations, and to better characterize the health risks of long-term low-level exposures. In any case, if there is an indirect damage. Without aquatic fauna, the river is less likely to generate quality water. And in the coming years, a catastrophic extinction of freshwater animals similar to the extinction of dinosaurs can be seen.

Transfers (the passage of water from one river to another), reservoirs, overfishing, leaks - diverting water for irrigation, for example - and climate change, which is reducing flows, make the situation much worse because it they move invasive species and reduce the chances of that river to dilute pollutants. In nature, less than $1 \%$ of the water is fresh water and man has to share it with animals.

Pharmaceutical contamination has also been observed in the sea. Certain hormonal compounds can cause severe estrogenic effects in fish, even in low concentrations. In the case of algae, in addition, the effects can be very serious, since sulfamethoxazole or diclofenac affect the function of their chloroplasts, responsible for the function of photosynthesis [34].

On the other hand, it has been described that drug contamination is concentrated in insects and passes to predators in water and soil. Insects transmit drug contamination to their predators. 60 pharmaceutical compounds have been detected in Australian brook insects, some in concentrations that can threaten animals that feed on them, such as trout and platypus. When these insects emerge as flying adults, medications can be passed to spiders, birds, bats and others that feed on streams. Insects transmit drug contamination to their predators. A platypus that lives in a stream that receives waters with pharmaceutical contamination could receive the equivalent of half the recommended dose of antidepressants for humans every day, just by eating its normal diet of creek insects. It is likely that this consumption has biological effects. The ecological consequences of exposure to this contamination are unknown. What effects does it mean for a platypus or trout to have more than 60 medications in your tissues? Are there synergistic effects? More research is needed on the extent of contamination of the food web and the effects of these compounds on fish and wildlife $[35,36]$.

Of course, solving the problem will require investments in infrastructure for wastewater treatment, stricter regulation and cleaning of already contaminated sites. Conventional water treatment processes, for example, chlorination, can eliminate approximately $50 \%$ of these compounds, while more advanced treatment processes, such as ozonation, advanced oxidation, activated carbon, nanofiltration and reverse osmosis can achieve higher elimination rates; Reverse osmosis, for example, can eliminate more than $99 \%$ of the large molecules of pharmaceutical products. The introduction of additional specialized and expensive systems for the treatment of drinking water, in particular to reduce trace concentrations of pharmaceutical products, is not considered necessary at this time, since the benefit to human health would be limited. The most appropriate approach to minimize the presence of pharmaceutical products in drinking water and reduce human exposure is to prevent or reduce its passage to the aquatic environment [30].

Thus, as the first cause is in inadequate polypharmacy [37] and in the lack of adherence, and these problems are within the scope of the GP's daily work, several actions could be advised at that level to health care:

-Avoiding polypharmacy

-Improving pharmacological compliance

-Educating patient on how to dispose of unused drugs (the rational elimination of drugs and pharmaceuticals, for example, avoiding throwing unused medicines down the toilet)

-Avoiding the use of over-the-counter drugs

\section{Conclusions}

Medicine tends to be a holistic discipline, according to which the individual must be treated as a whole and provide comprehensive biopsychosocial health care related to physiology, biochemistry, nutrition, exercise, social relationships... and also habitat, environment and ecology.

Although the GP may not be aware of this, there are a number of actions during daily work in general medicine, which affect to contextual and environmental 
risks, and their individual, epidemiological and ecological practical applications involved in their knowledge are important for GPs training in skills that transcend current the specialty boundaries.

The GPs must be aware not only of the profound physiological effects of the psychosocial in patients and of the psychosocial in the biological, but also of the repercussions on the global ecological system of the (apparently) small "micro" decisions in the individual; at clinical level with the patient. In general medicine, tasks carried out at a small calibre level can subtly tilt the world towards ecology, dignity, compassion, and health.

In any case, it is clear that individual actions are important to combat climate change, but they should not make us forget the importance of the great changes that can really make a difference.

\section{References}

1. Davidoff F (2019) Understanding contexts: how explanatory theories can help. IS 14.

2. Turabian JL (1995) Notebooks of Family and Community Medicine. An introduction to the principles of Family Medicine. Madrid, Diaz de Santos.

3. Walker JV (1951) Health and the citizen. A study in desing for living. London: The World affairs Book Club.

4. Salas RN, Jha AK (2019) Climate change threatens the achievement of effective universal healthcare. BMJ 366.

5. Suarez F (2006) Around the idea of "situation diagnosis". Article in Spanish. Area 3. Numero Especial. Congreso Internacional "Actualidad del Grupo Operativo", Madrid.

6. Dilani A (2001) Psychosocially supportive design-Scandinavian health care design. World Hosp Health Serv 37(1): 20-24, 33, 35.

7. Theall KP, Shirtcliff EA, Dismukes AR, Wallace M, Drury SS (2017) Association Between Neighborhood Violence and Biological Stress in Children. JAMA Pediatr 171(1): 53-60.

8. MacBride-Stewart S, Butler C, Fox NJ (2019) Editorial: Special Issue on Society, Environment and Health. Health 23(2): 117-121.
9. Logan AC, Selhub EM (2012) Viz Medicatrix Naturae: does nature "minister to the mind"? BiopsychoSocial Medicine 6.

10. Yuill C, Mueller-Hirth N, Tung NS, Kim Dung NT, Tram PT, et al. (2019) Landscape and well-being: A conceptual framework and an example. Health 23(2): 122-138.

11. MacBride-Stewart S (2019) Atmospheres, landscapes and nature: Off-road runners' experiences of well-being. Health 23(2): 139-157.

12. Akst J (2019) Time Spent in Nature Is Good for You. The Scientist.

13. Wolf KL, Housley E (2016) The benefits of nearby nature in cities for older adults. Annapolis, MD: TKF Foundation.

14. Keinanen M (2015) Taking your mind for a walk: a qualitative investigation of walking and thinking among nine Norwegian academics. High Educ (Dordr) 71(4): 593-605.

15. Kramer CK, Mehmood S, Suen RS (2019) Dog Ownership and Survival. A Systematic Review and Meta-Analysis. Cardiovascular Quality and Outcomes 12(10).

16. Mubanga $M$, Byberg L, Egenvall $A$, Ingelsson E, Fall T (2019) Dog Ownership and Survival After a Major Cardiovascular Event. A Register-Based Prospective Study. Cardiovascular Quality and Outcomes $12(10)$.

17. Kazi DS (2019) Who Is Rescuing Whom? Dog Ownership and Cardiovascular Health. Circ Cardiovasc Qual Outcomes 12(10).

18. Fall T, Lundholm C, Ortqvist AK (2015) Early Exposure to Dogs and Farm Animals and the Risk of Childhood Asthma. JAMA Pediatr 169(11).

19. Harris N (1999) Building Lives: Constructing Rites and Passages. Yale University Press, New Haven, London.

20. Loxterkamp D, Snider B (2015) What doctors have in common with architects-part 1: A manual art. BMJ 350.

21. Turabian JL, Perez-Franco B (2016) The Family Doctors: Images and Metaphors of the Family Doctor to Learn Family Medicine. Nova Publishers, New York. 


\section{Epidemiology International Journal}

22. Baur N (2019) 'This weather always gets me down': A psychosocial perspective on mental illness. Health 23(2): 180-196.

23. Cole DC, Eyles J, Gibson BL, Ross N (1999) Links between humans and ecosystems: the implications of framing for health promotion strategies. Health Promot Int 14(1): 65-72.

24. Turabian JL (2018) Ecological Implications of Decisions in the Individual Patient: Concentric Health Circles. Chronicle of Medicine and Surgery 2(2): 104-9.

25. Wilson C, Tisdell C (2001) Why farmers continue to use pesticides despite environmental, health and sustainability costs. Ecol Econ 39(3): 449-462.

26. Carvalho FP (2006) Agriculture, pesticides, food security and food safety. Environ Sci Policy 9(7-8): 685-692.

27. Mufson S (2019) The trouble with chocolate. A decade after Mars and other chocolate makers vowed to stop rampant deforestation, the problem has gotten worse. The Washington Post.

28. Clark MA, Springmann M, Hill J, Tilman D (2019) Multiple health and environmental impacts of foods. Proceedings of the National Academy of Sciences.

29. Fuster V, Sampedro JL (2009) La ciencia y la vida. Barcelona: Ramdom House Mondadori, S.A. P.
30. Turabian JL (2018) Why do Patients Not Meet The Pharmacological Treatment? Arch Pharmacol Ther 1(1): 1-8.

31. Turabian JL (2018) Why do Patients Not Meet The Pharmacological Treatment? Arch Pharmacol Ther 1(1):1-8

32. Ennis MV (2011) Medicines pollute rivers more than industries. El Pais.

33. Matthews-King A (2019) Drug pollution in rivers reaching damaging levels for animals and ecosystems, scientists warn. Independent.

34. Anonymous (2016) Drugs and other emerging pollutants would endanger the waters of rivers and seas. Correo Farmaceutico.

35. Richmond EK, Rosi EJ, Walters DM, Fick J, Hamilton SK, et al. (2018) A diverse suite of pharmaceuticals contaminates stream and riparian food webs. Nat Commun 9(1).

36. Anonymous (2018) Drug contamination is concentrated in insects and passes to predators in the water and on the ground. El Medico Interactivo.

37. Turabian JL (2019) Polypharmacy is an Indicator of Bad Practice and Low Quality in General Medicine. J Qual Healthcare Eco 2(4): 1-8. 